\title{
IMAGE DATA CLASSIFICATION BY NFES-MODEL
}

\author{
M. Givi Efgivia' ${ }^{1)}$ and Safaruddin A. Prasad ${ }^{2)}$ \\ ${ }^{1)}$ Sekolah Tinggi Manajemen Informatika dan Komputer Muhammadiyah Jakarta, 10340 \\ ${ }^{2)}$ Program Studi Fisika, Jurusan Fisika, FMIPA, UNHAS, Makassar \\ E-mail : ausanaprasad@yahoo.com, au3sa4na5@yahoo.co.id
}

\begin{abstract}
In this paper, we propose an identification method of the land cover from remote sensing data with combining neuro-fuzzy and expert system. This combining then is called by Neuro-Fuzzy Expert System Model (NFES-Model). A Neural network (NN) is a part from neuro-fuzzy has the ability to recognize complex patterns, and classifies them into many desired classes. However, the neural network might produce misclassification. By adding fuzzy expert system into NN using geographic knowledge based, then misclassification can be decreased, with the result that improvement of classification result, compared with a neural network approximation.
\end{abstract}

Keywords: knowledge-based, neuro-fuzzy, expert system, classification, misclassification.

\section{INTRODUCTION}

Neuro-fuzzy expert system model (NFES Model) can be divided into two sub-systems which consist of neuro-fuzzy system and expert system. Neuro-fuzzy system is a combination of neural networks and fuzzy systems, where each has independent areas. The connections to each other are merely marginal but both bring benefit for the solution of many problems.

Lotfi A. Zadeh introduced the concept of fuzzy sets in 1965. In 1974, E.H. Mamdani invented a fuzzy inference procedure, thus setting the stage for initial development and proliferation of fuzzy system applications. Logic programming also played an important role in disseminating the idea of fuzzy inference, as it emphasizes the importance of nonnumerical knowledge over traditional mathematical models [4].

Expert systems are computer programs which use symbolic knowledge to simulate the behavior of human experts, and they are a topical issue in the field of artificial intelligence (AI). However, people working in the field of AI continue to be confused about what AI really is proposed by Schank [6]. In other words, there are attempts to conf properties (or attributes) to a computer system under the guise of AI, but the practitioners find difficulty in defining these properties! It is generally accepted that an expert system is useful when it reaches the same conclusion as an expert [7].

The most recent wave of fuzzy expert system technology uses consolidated hybrid architectures, what we call Synergetic AI. These architectures developed in response to the limitations of previous large-scale fuzzy expert systems.
The NFES-Model is developed and implemented to analyze of land cover classification on the field of Maros District on South Sulawesi Province, Indonesia.

The fuzzy logic is used to analyze of remote sensed data for land cover classification since Maros District is complex geography, the remotely sensed image has various geometrical distortions caused by an effect the complex earth surface, such as the shadow of hills.

Remotely sensed image data sampled from a satellite includes specific problems such as large image data size, difficulty in extracting characteristics of image data and a quantity of complex geographical information in a pixel due to its size of $30 \mathrm{~m}^{2}$. In the past, we have used a statistical method such as a maximum likelihood method without considering these problems. The maximum likelihood method identifies a recognition structure by a statistical method using the reciprocal relation of density value distribution per one category. This method is based on an assumption that image data follows the Gaussian distribution.

An image data classification may be inserted by the secret information for intelligence requires or information hiding art on the image data by the steganography method. Now, if a governance institute to obtain the image data received, then to appear ask, what that image data is contain the secret information?

Signal of an image data classification or other image data can be checked by using a fast Fourier transform algorithm. This checking the main for uncovering the secret screen is entered in to image data received. 


\section{NEURO-FUZZY EXPERT SYSTEM (NFES)}

\section{Architecture of NFES-Model}

Figure 1 showed NFES-Model architecture as neural network (NN) architecture with four hidden layers, one input layer, and one output layer. In this NFES-Model architecture showed parallel structure and data followed in the model, respectively for learning (backward path) and classification (forward path). It is in the image data processing will be improved upon classification result and the image classification can be visualized.

Each layer in the NFES-Model (Figure 1) is associated by certain stage in the fuzzy inference processing. In completely, each layer is explanation contain as follows:

Layer-1: The input layer. Each neuron in this layer transmits external crisp signals directly to the next layer. That is,

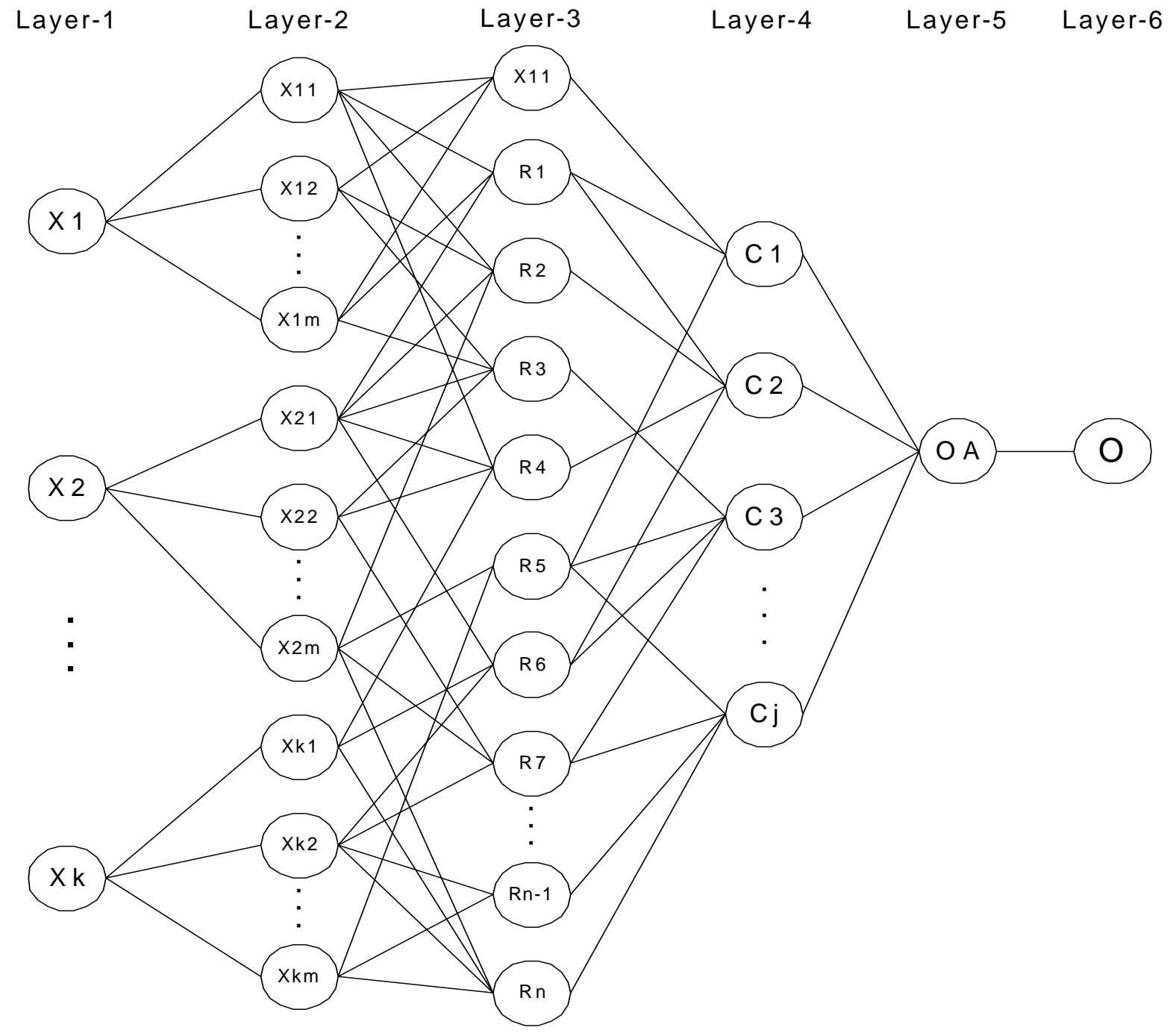

$$
y_{i}^{(1)}=x_{i}^{(1)}
$$

Layer-2: The fuzzification layer. Neurons in this layer represent fuzzy sets used in the antecedents of fuzzy rules. A fuzzification neuron receives a crisp input and determines the degree to which this input belongs to the neuron's fuzzy set. The activation function of a membership neuron is set to the function that specifies the neuron's fuzzy set. We use triangular sets, and therefore, the activation functions for the neurons in layer- 2 are set to the triangular membership functions. A triangular membership function can be specified by two parameters $\{\mathrm{a}, \mathrm{b}\}$ as follows:

$$
y_{i}^{(2)}=\left\{\begin{array}{lll}
0,- & \text { if } & x_{i}^{(2)} \leq a-\frac{b}{2} \\
1-\frac{2\left|x_{i}^{(2)}-a\right|}{b}, & \text { if } & a-\frac{b}{2}<x_{i}^{(2)}<a+\frac{b}{2} \\
0,- & \text { if } & x_{i}^{(2)} \geq a+\frac{b}{2}
\end{array}\right.
$$
Layer-4 
Layer-3: The fuzzy rule layer. Each neuron in this layer corresponds to a single fuzzy rule. A fuzzy rule neuron receives inputs from the fuzzification neurons that represent fuzzy sets in the rule antecedents. For instance, neuron R1, which corresponds to Rule-1, receives inputs from neurons PR1, PR2, and PR3.

In a neuro-fuzzy system, intersection can be implemented by the product operator. Thus, the output of neuron I in layer-3 is obtained as:

$$
\begin{aligned}
& y_{i}^{(3)}=x_{1 i}^{(3)} \times x_{2 i}^{(3)} \times \ldots \times x_{k i}^{(3)} \\
& y_{R 1}^{(3)}=\mu_{P R 1} \times \mu_{P R 2} \times \mu_{P R 3}=\mu_{R 1}
\end{aligned}
$$

Layer-4: The output membership layer. Neurons in this layer represent fuzzy sets used in the consequent of fuzzy rules.

Each output membership neuron combined all its inputs by using the fuzzy operation union. This operation can be implemented by the probabilistic $\mathrm{OR}(\oplus)$. That is,

$$
\begin{aligned}
& y_{i}^{(4)}=x_{i 1}^{(4)} \oplus x_{2 i}^{(4)} \oplus \ldots \oplus x_{k i}^{(4)} \\
& y_{O i}^{(4)}=\mu_{R 2} \oplus \mu_{R 3} \oplus \mu_{R 4} \oplus \mu_{R 6} \oplus \mu_{R 7} \oplus \mu_{R 8}=\mu_{O 1}
\end{aligned}
$$

Layer-5: The defuzzification layer. Each neuron in this layer represents a single output of the neurofuzzy expert system. All neurons in layer- 4 are combines them in to a union operation for product operation results, and it is called a sum-product composition.

$$
y=\frac{\mu_{01} \times a_{O 1} \times b_{01} \oplus \mu_{02} \times a_{O 2} \times b_{O 2} \oplus \ldots \oplus \mu_{07} \times a_{07} \times b_{O 7}}{\mu_{01} \times b_{O 1} \oplus \mu_{O 2} \times b_{O 2} \oplus \ldots \oplus \mu_{07} \times b_{O 7}}
$$

The next operation is defuzzification to be input for neuron in the next layer.

Layer-6: The output networking. The neuron in this layer is accumulation of all processing series in NFES networking. In the NFES implementation, the neuron in the layer- 6 is appears as classification map.

Each input variables is used on the networks, we must established haw much the fuzzy sets are used for the domain partition of each variable. By the domain partition for each variable and linguistic terms, then we can do classification and we are obtained it classification result [5].

\section{Algorithm NFES}

An algorithm presented of NFES-Model to land cover identification. The NFES algorithm can be written with detailed as follow as:

Step-1: Determine number of $m$-th membership functions for k-th inputs
Step-2: Rule generated for $j$-th class

Step-3: Make a training and error calculate in $j$-th class $\left(\in_{j}\right)$ with the formula

$\epsilon_{j}=\frac{\sqrt{\sum_{k=1}^{3} \sum_{i=1}^{N}\left(x_{i}^{k}-G_{i}^{k}\right)^{2}}}{3^{*} N}$

Which,

$N=$ number of pixels in the j-th class

$x=$ value of pixel in the classification image

$G=$ value of pixel in the ground-truth image.

Then index of three (3) showed the input data is consist of three channels.

Step-4: $I F \in_{j}>\epsilon_{t}$ THEN return to step-2 ( $t=$ tolerance)

Step-5: make the step-4 until $k^{m}$ iteration

Step-6: IF $\in_{j}>\in_{t}$ THEN return to step-1

Step-7: $\in_{j}<\in_{t}$ THEN $C=\left\{x \mid x \in C_{j}\right\}$. This expression showed that $C$ is a set which the elements are $x$ such as $x$ is element of $\mathrm{j}$-th class.

\section{THE EXPERIMENTAL DESIGN}

Figure 2 showed the land cover classification procedure scheme of NFES-Model. The image data classification using neuro-fuzzy expert system (NFES) is divided became of three partition, that is namely, pre-processing by fuzzy c-mean method, pattern recognition by neuro-fuzzy system, and the checking by knowledge representation.

\section{Pre-processing by Fuzzy C-Mean}

Clustering implies a grouping of pixels in multispectral space. Pixels belonging to a particular cluster are therefore spectrally similar. Fuzzy C-Mean (FCM) is a one from grouping is based Euclidian distance. Prasad [6] group using FCM algorithms to land cover classification. Such as is carried out by Sangthongpraow [7] group also.

If $\boldsymbol{x}_{\mathbf{1}}$ and $\boldsymbol{x}_{\mathbf{2}}$ are two pixels whose similarity is to be checked then the Euclidean distance between them is

$$
\begin{aligned}
d\left(x_{1}, x_{2}\right) & =\left\|x_{1}-x_{2}\right\| \\
& =\left\{\left(x_{1}-x_{2}\right)^{t}\left(x_{1}-x_{2}\right)\right\}^{1 / 2} \\
& =\left\{\sum_{i=1}^{N}\left(x_{1 i}^{2}-x_{2 i}^{2}\right)\right\}^{1 / 2}
\end{aligned}
$$

Where $N$ is number of spectral components. 


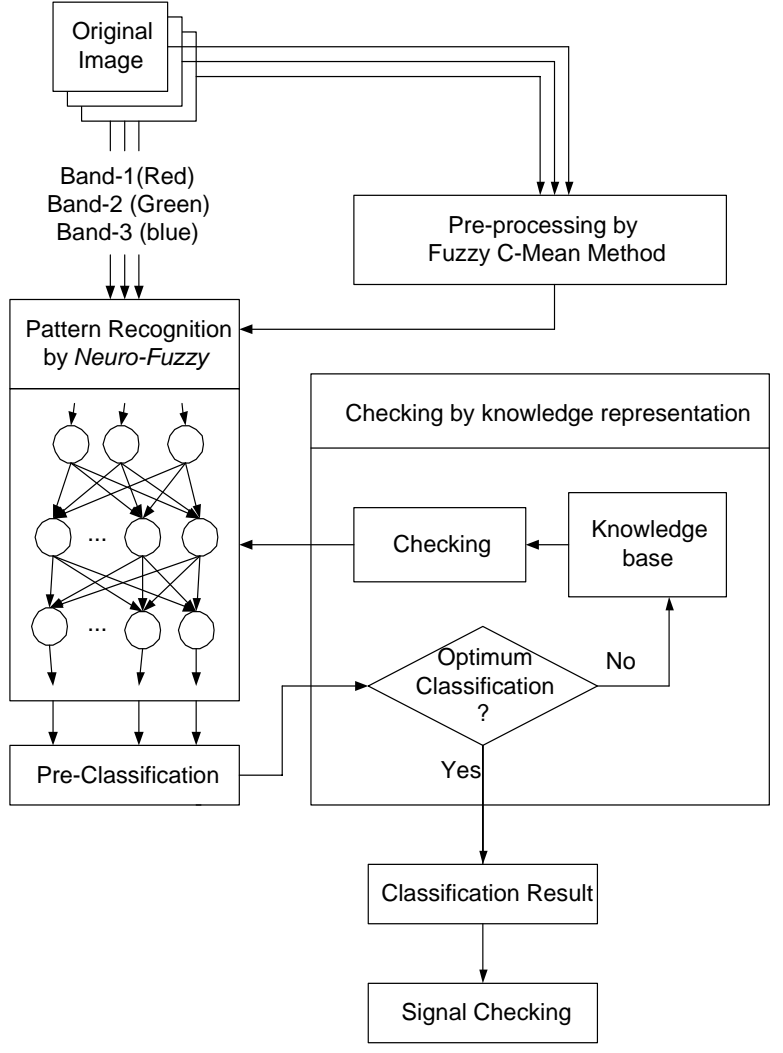

Figure 2. The NFES-Model procedure scheme for land covers classification

A common clustering criterion or quality indicator is the sum of squared error (SSE) measure, defined as:

$$
\begin{aligned}
\text { SSE } & =\sum_{C_{i}} \sum_{x \in C_{i}}\left(x-M_{i}\right)^{t}\left(x-M_{i}\right) \\
& =\sum_{C_{i}} \sum_{x \in C_{i}}\left\|x-M_{i}\right\|^{2}
\end{aligned}
$$

Where $M_{i}$ is the mean of the i-th cluster and $x \in C_{i}$ is a pattern assigned to that cluster $[6,7]$.

\section{Pattern Recognition by Neuro-Fuzzy System}

In this part, do it processing in to four steps. The first step is fuzzification processing of crisp value. The second step is editing of membership function, include to determining of number of membership function for each input. The thirth step is training and testing process. The fourth step is defuzzification processing for pre-classified requirement.

The next step is checking the pre-classified result. What it optimal classification or not? If pre-classified result or next classified result is not optimal yet, then the up-dated of knowledge base and then checking classified in loop. Optimalization of classified is doing by seek number of misclassification. If the value of misclassification to reaches is desire, then the checking is stopped. Then we obtained the final classification. From the final classification result, we are checking it image about the existing of signal noise or secret information inserted. Signal checking it using the Fast Fourier Transform (FFT).

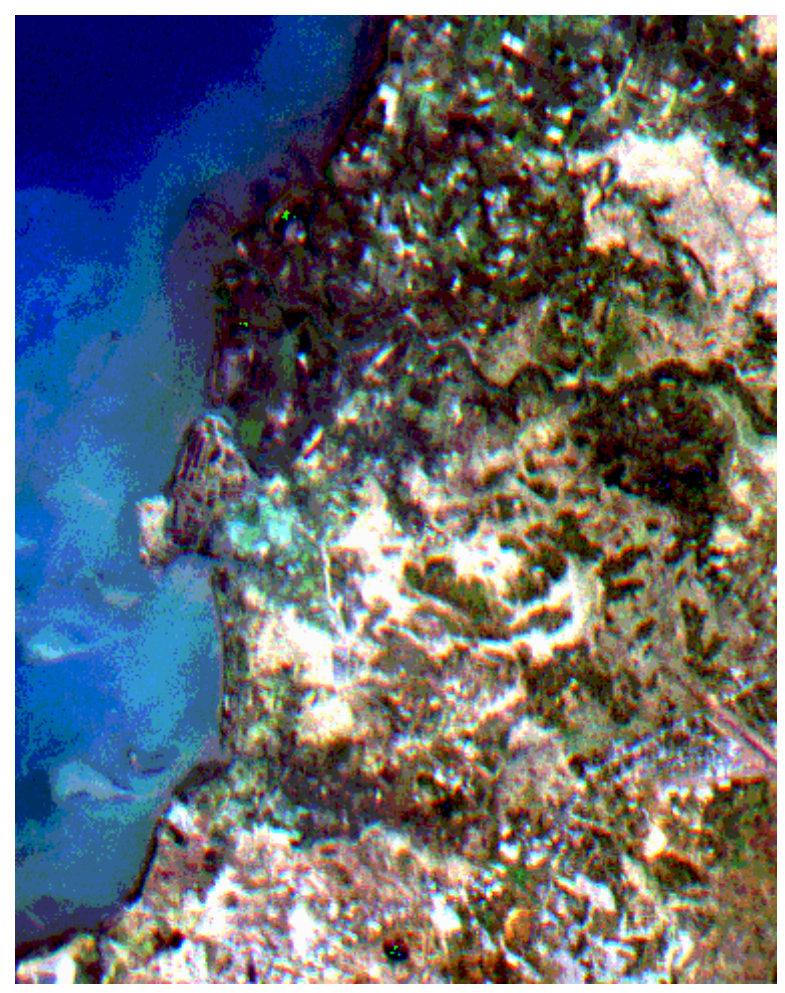

Figure 3. Landsat ETM7 image of false color composite (band-1, band-2, band-3) in year of 2001 from Marusu Districk in South Sulawesi.

\section{The Checking by Knowledge Representation}

Table 1 shows about premis categories for production rules of network structure of NFES-Model.

Table 1. Premis category for production rules

\begin{tabular}{ccl}
\hline $\begin{array}{c}\text { Premis } \\
\text { category }\end{array}$ & $\begin{array}{c}\text { Interval in } \\
\text { Symbols }\end{array}$ & \multicolumn{1}{c}{ Mean of symbols } \\
\hline 1 & $0 \leq x \leq 49$ & Least value (PR) \\
2 & $49<\mathrm{x} \leq 101$ & Small value(RS) \\
3 & $101<\mathrm{x} \leq 150$ & Medium small (SB) \\
4 & $150<\mathrm{x} \leq 202$ & Medium value(SA) \\
5 & $202<\mathrm{x} \leq 251$ & Large value (TS) \\
6 & $251<\mathrm{x} \leq 255$ & Most value (PT) \\
\hline
\end{tabular}

With the premis category for production rules, then attribute items to become "what the pixel value to be appropriated with the mean symbol in table-1?". And because network structure is consist of three inputs, then atribut items will become 18 kinds $(3 \times 6)$. 
Inference result by forward chaining method will be reduced of rules to be except 8 rules. If $R$ is value of pixels in band-1, $\mathrm{G}$ is value of pixels in band-2, and $\mathrm{B}$ is value of pixels in band-3, then the eight rules each is 1. IF R least value AND G least value AND B least value OR R small value THEN classified is Hutan (forest)
2. IF R least value AND G least value OR G small value OR G medium small AND B small value OR B medium small OR B medium value THEN classified is Air (water)

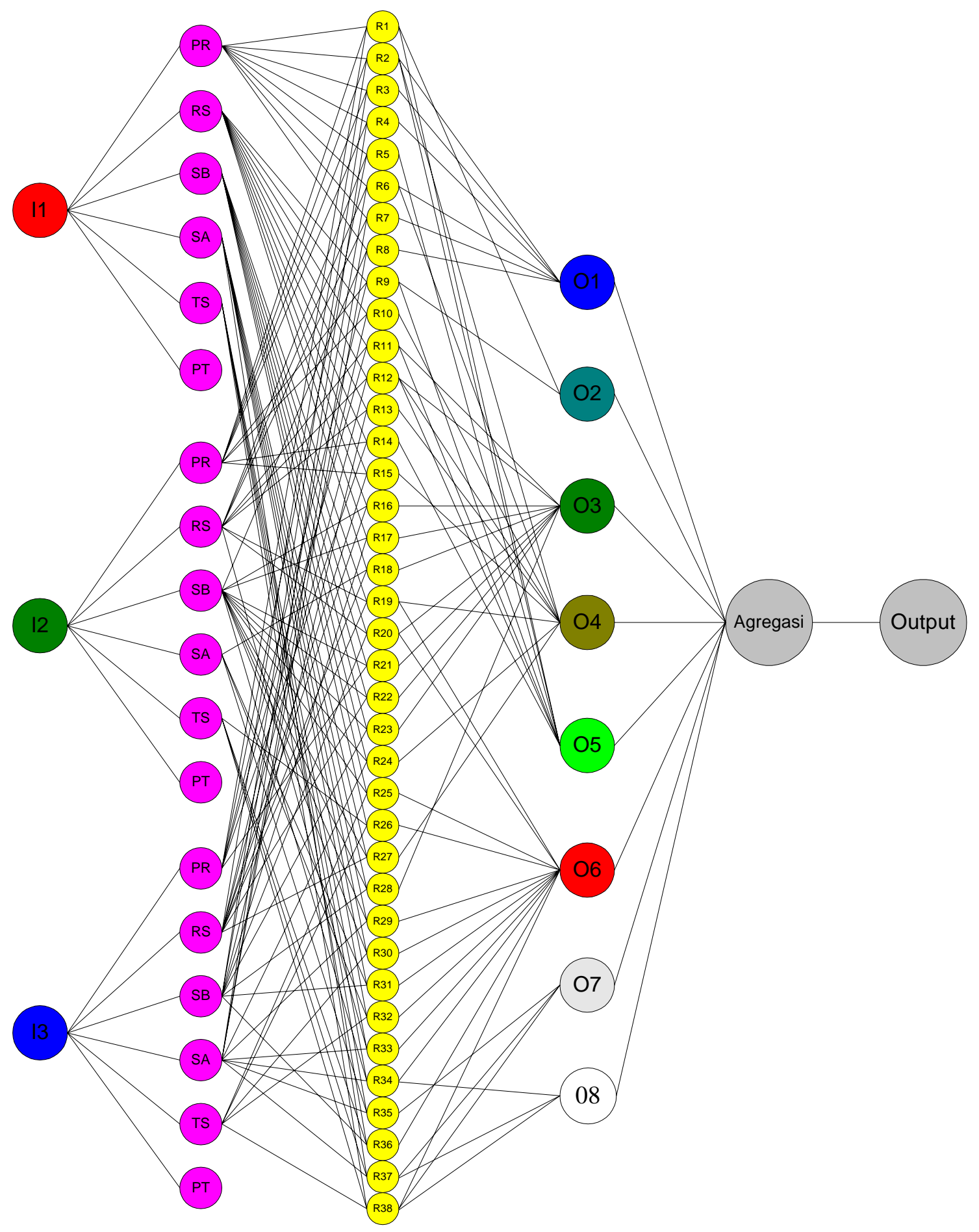

Figure 4. The network structure of NFES-Model created by rule production 
3. IF R least value

OR R small value

AND G least value

OR G small value

AND B least value

THEN classified is Tegalan/kebun (garden)

4. IF R small value

OR R medium small

OR R medium value

AND G least value

OR G small value

OR G medium small

AND B small value

OR B medium small

OR B medium value

THEN classified is Tambak (embankment)

5. IF R small value

OR R medium small

OR R medium value

AND G small value

OR G medium small

OR G medium value

AND B least value

OR B small value

OR B medium small

THEN classified is Sawah (paddy field)

6. IF R medium small

OR R medium value

AND G small value

OR G medium small

AND B medium small

OR B medium value

THEN classified is pemukiman (urban)

7. IF R medium value

AND G medium value

OR G large value

AND B large value

THEN classified is lahan gundul (bare land)

8. IF R large value

AND G medium value

OR G large value

AND B medium value

OR B large value

THEN classified is awan (cloud).

The visualization of all rules in the computer screen can be seen as in Figure 4.

\section{DISCUSSION AND RESULT}

A supervised learning algorithm of NFES to adapted the fuzzy sets is continuously a cyclic via learning sets until has obtain the final criterion is appropriate, for example, if number of misclassification to indicate the value is acceptance well be reached, or error value can't decrease again.

In Table 2, presented the land cover classification result in Marusu District, South Sulawesi, Indonesia, and land cover area with the assumption that each pixels look after the interest of $30 \mathrm{~m}^{2}$ area of land.
Classification using NFES in a form of knowledge based expert system. Development of the rule base referred by two circumstances, namely, the map information (earth form) and geographic knowledge.

As the implemented of the NFES-Model, we are demonstrated of the image classified result is showed in Figure 4, where the image classification are consist of water area (Air), forest area (Hutan), paddy field area (Sawah), embankment area (Tambak), garden area (Tegalan/Kebun), urban area (Urban), bare land area (Lgdl), and cloud area (Awan). From the calculation result, we are obtained the tabulation data of classified result as showed in Table 2. The training error by back-propagation method to get value is 6.6365 for 100 iteration, and error 0.68957 for 1000 iteration. Then with used the method is propose, we are obtain error at same 0.00013376 .

Table 2. Calculation Result

\begin{tabular}{lcc}
\hline \multicolumn{1}{c}{ Object } & $\begin{array}{c}\text { Number of } \\
\text { pixels }\end{array}$ & $\begin{array}{c}\text { Areas } \\
\text { (ha) }\end{array}$ \\
\hline Water (Air) & 52563 & 15769 \\
Forest (Hutan) & 59940 & 17982 \\
Paddy field (Sawah) & 18720 & 5616 \\
Embankment (Tambak) & 14789 & 4437 \\
Garden (Kebun) & 3363 & 1009 \\
Urban (Pemukiman) & 28014 & 8404 \\
Bare land (Lahan gundul/Lgdl) & 4293 & 1288 \\
The covered of Cloud (Awan) & 871 & 261 \\
Classified area & 182553 & 54766 \\
Survey area (size: 483 x 381) & 184023 & 55207 \\
Unclassified area & 1470 & 441 \\
Percent classified & $99.20 \%$ & \\
Percent unclassified & $0.80 \%$ & \\
\hline
\end{tabular}

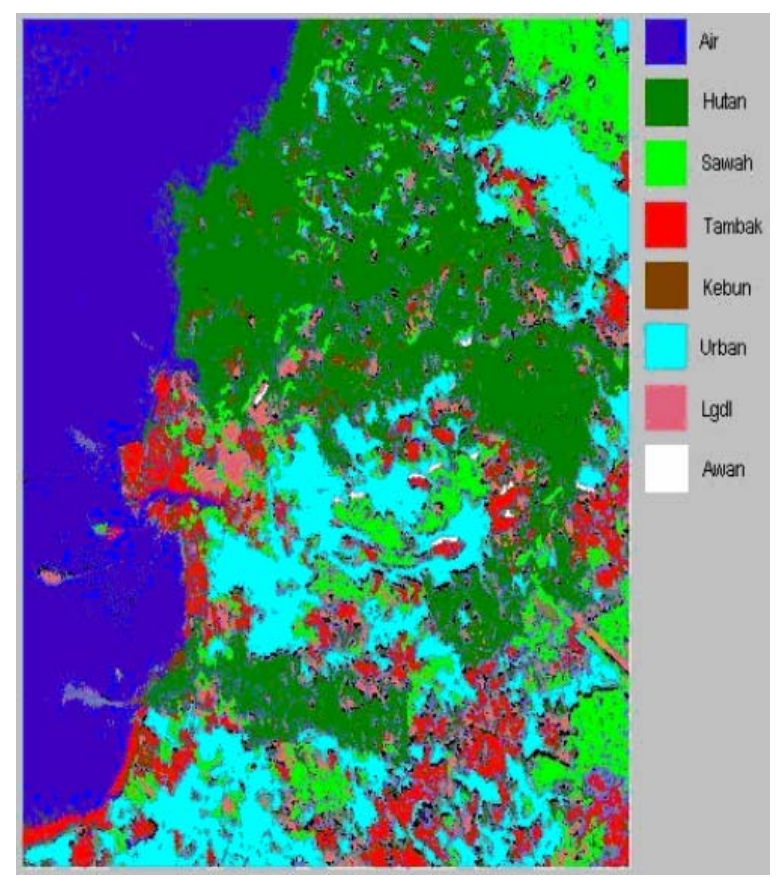

Figure 5. The land covers classification of Marusu, South Sulawesi, Indonesia 


\section{CONCLUSION}

Verification result using by NFES-Model to land cover classified has been showed decreases of misclassification. With using artificial neural network approximation, or back-propagation neural network (BPNN), misclassification up to $20 \%$ (investigation result to obtain $12.29 \%$ ), then if using the NFESModel, with the test-case using LandSat-ETM7 data of Marusu District, South Sulawesi, misclassification is $0.8 \%$ only.

\section{REFERENCES}

1. Funabashi, M., Maeda, A., Morooka, Y., dan Mori, K. 1995. Fuzzy and neural hybrid expert system: Synergetic AI, IEEE Expert, pp. 32-40.

2. Skidmore, A., Watford, F., Luckanarug, P., dan Ryan, P. 1996. An operational GIS expert system for mapping forest soil, Photogrammetric Engineering \& Remote Sensing Vol.62, No.5, pp. 501-511.

3. Maeda, A. et al. 1991. A fuzzy-based expert system building tool with self-tuning capability for membership function, Proc. World Congress on Expert Systems, Pergamon Press, New York, pp. 639-647.

4. Murai, H. dan Omatu, S. 1997. Remote sensing image analysis using a neural network and knowledge based processing, Int. J. Remote Sensing, Vol.18, No.4, pp. 811-828.
5. Jang, J. S. R., 1993. ANFIS: Adaptive-Networkbased Fuzzy Inference Systems, IEEE Transactions on Systems, Man, and Cybernetics, Vol. 23, No. 3, pp. 665-685.

6. Prasad, S.A., Sadly, M., dan Sardy, S., 2002. Landsat TM Image data Classification of Land Cover by Fuzzy C-Mean, Proc of the Int. Conf. on Opto electronics and Laser Applications ICOLA'02, pp. D36-D39, October 2-3, 2002, Jakarta, Indonesia. (ISSN : 979-8575-03-2)

7. Sangthongpraow, U., Thitimajshima, P., dan Rangsangseri, Y., 1999. Modified Fuzzy C-Means for Satellite Image Segmentation, GISdevelopment.net.

8. Enbutu, I., Baba, K., Hara, N., Waseda, K., dan Nogita, S. 1994. Integration of multi-AI paradigms for intelligent operation support systems: Fuzzy rule extraction from a neural network, Water Science and Technology, Vol. 28, no. 11-12, pp. 333-340.

9. Nauck, U. dan Kruse, R. 1999. Design and implementation of a neuro-fuzzy data analysis tool in java, Thesis Diploma, Braunschweig.

10. Simpson, J.J. dan Keller, R.H. 1995 An Improved Fuzzy Logic Segmentation of Sea Ice, Clouds, and Ocean in Remotely Sensed Arctic Imagery, Remote Sens. Environ. Vol.54, pp. 290 - 312. 